\title{
Say No To Bully! Kind Words Build A Wonderful World
}

\author{
Yani Octafia $^{1^{*}}$, Dwi Rahayu ${ }^{2}$, Rossy Halimatun Rosyidah ${ }^{3}$, Ismi \\ Adinda $^{4}$, Afrianti Wulandari ${ }^{5}$.
}

Universitas Pamulang

*E-mail: dosen01153@Unpam.ac.id

\begin{abstract}
Bullying behavior has a lot of bad effects, both verbal and nonverbal. This bad behavior is something that is often done by some children at this time, both in their home and school environment. Bullying is a phenomenon that often goes unnoticed by us as the general public and among schools. We, from the Community Service Program team, Universitas Pamulang want to contribute to providing anti-bullying counseling to school children at the Ciputat Community Reading Park, the goal is to minimize bullying, and improve children's intelligence in socializing. Taman Baca Masyarakat (TBM) was chosen because there were many students gathered there, there were 50 people from different schools, from Play Group level to high school. The solutions proposed or offered in this Community Service activity include: 1) Fairy tales with anti-bullying themes, 2) Anti-bullying education, and 3) Creating anti-bullying posters. The approach method used in Community Service activities is mentoring carried out by brainstorming. Output Based on the proposed problem solution is for children to understand about the dangers of bullying so that reducing bullying at school increases children's awareness of their friends, and gets along well and cooperatively.
\end{abstract}

Keywords: Bullying, expressions, vocabulary

\begin{abstract}
Abstrak
Perilaku bullying memiliki banyak dampak buruk, baik verbal maupun nonverbal. Perilaku buruk ini merupakan hal yang sering dilakukan oleh sebagian anak saat ini, baik di lingkungan rumah maupun sekolahnya. Bullying merupakan fenomena yang sering luput dari perhatian kita sebagai masyarakat umum dan antar sekolah. Kami dari tim Program Pengabdian Masyarakat (PkM) Universitas Pamulang ingin berkontribusi memberikan penyuluhan anti bullying kepada anak sekolah di Taman Baca Komunitas Ciputat, tujuannya adalah meminimalisir bullying, dan meningkatkan kecerdasan anak dalam bersosialisasi. Taman Baca Masyarakat (TBM) dipilih karena banyaknya siswa yang berkumpul disana, terdapat 50 orang dari berbagai sekolah, dari tingkat Play Group hingga SMA. Solusi yang diusulkan atau ditawarkan dalam kegiatan Pengabdian kepada Masyarakat ini antara lain: 1) Dongeng dengan tema anti bullying, 2) Pendidikan anti bullying, dan 3) Membuat poster anti bullying. Metode pendekatan yang digunakan dalam kegiatan Pengabdian kepada Masyarakat $(\mathrm{PkM})$ adalah pendampingan yang dilakukan dengan brainstorming. Output berdasarkan solusi masalah yang diajukan adalah agar anak memahami tentang bahaya bullying sehingga pengurangan bullying di sekolah meningkatkan kesadaran anak terhadap teman-temannya, dan rukun serta kooperatif.
\end{abstract}

Kata kunci: ekspresi, kosakata, penindasan 


\section{A. Pendahuluan}

Akhir-akhir ini dunia pendidikan Indonesia menjadi pusat perhatian karena banyak kasus bullying yang diberitakan di dunia maya. Tindakan bullying bisa terjadi pada siapa saja dan dimana saja, tidak menutup kemungkinan di sekolahsekolah sekitar kita, terutama bullying secara verbal. Contoh kecil salah seorang siswa dijuluki "si amis" karena orang tuanya berprofesi sebagai pedagang ikan di pasar. Selain itu ada juga yang memanggil teman bukan dengan namanya melainkan dengan sebutan "ndut","njing (anjing)" atau hal-hal lain yang tidak baik. Ciri-ciri bullying adalah adanya perilaku agresif yang terjadi berulang-ulang dan terus menerus dan adanya kekuatan yang tidak seimbang antara pelaku dan korban (Olweus 1993, dalam Anggraeni, dkk 2016). Berdasarkan hasil observasi pada keadaan dan pemberitaan anak-anak usia sekolah di Indonesia di ketahui bahwa para pelajar mengalami krisis bullying dengan maraknya kasus bullying hingga mengorbankan nyawa. Masalah selanjutnya adalah tindakan bullying bisa terjadi pada siapa saja dan dimana saja, tidak menutup kemungkinan di sekolahsekolah sekitar kita,

Akibatnya korban bullying mengalami rasa sakit secara fisik, emosi, dan psikologis. Tujuan umum dari kegiatan Pengabdian kepada Masyarakat (PkM) ini adalah mencegah tindakan bullying. Sesuai dengan yang diinstruksikan oleh Presiden Jokowi Dodo bahwa tidak hanya lingkungan keluarga dan sekolah saja yang harus mencegah kekerasan terhadap anak/bullying, melainkan masyarakat pun harus turut serta berpartisipasi. Menurutnya ada banyak cara yang bisa dilakukan sebagai bentuk aksi pencegahan bullying, sebagai berikut; "Aksi pencegahan dilakukan dengan berbagai model kampanye, model - model sosialisasi dan edukasi publik yang bukan hanya menarik, tetapi memunculkan kepedulian sosial pada persoalan kekerasan pada anak", (lokadata.id, 10 Januari 2020).

Macam-macam bullying menurut HUMAS Kota Bandung dalam (TribunJabar.com, 24 Juli 2017), diantaranya adalah:

1) bullying fisik, yaitu memukul, mencuri, merusak barang, mendorong, atau melakukan tindakan merugikan secara fisik pada seseorang secara berulang.

2) bullying sosial, yaitu menyebarkan gosip atau rumor bohong, menjauhi seseorang dan mengajak orang lain untuk ikut menjauhinya, ikut campur urusan orang lain dan menyebarkannya.

3) bullying verbal, yaitu menghina, mengancam, ataupun menyindir dengan julukan negatif. Tidak selalu hanya terkait hal-hal fisik, ejekan, atau hinaan, bisa juga terkait suku, agama, ras, etnis, status ekonomi, orientasi seksual, dan banyak hal lainnya.

4) bullying ciber yaitu; berkomentar kasar, menjatuhkan pihak tertentu, mengancam, menyakiti, memata-matai kehidupan orang melalui sosial media lalu menyebarkannya.

Bullying dan dampaknya sudah banyak menyorot perhatian berbagai pihak bukan baru-baru ini saja, Menurut Sejiwa (2008), bullying adalah tindakan penggunaan kekuasaan untuk menyakiti seseorang atau sekelompok orang baik secara verbal, fisik, maupun psikologis sehingga korban merasa tertekan, trauma, 
dan tak berdaya. Selain itu menurut Yuyarti (2018:170), bullying merupakan serangan berulang secara fisik, psikologi, sosial, ataupun verbal yang dilakukan oleh teman sebaya kepada teman yang lebih lemah untuk mendapatkan keuntungan atau kepuasan mereka sendiri. Rigby (2007) dalam Anggraeni, dkk (2016) menjelaskan dampak bullying bagi pelajar yaitu menambah level kecemasan, hilangnya rasa percaya diri self-esteem, meningkatkan symptoms psikosomatik, seperti sakit kepala, sakit perut, dan luka pada mulut bibir, dan mempunyai pemikiran merasa dikucilkan dari sekolah. Menurut psikolog klinis Liza Marielly Djaprie, bullying verbal lebih berbahaya dibanding bullying fisik. Efeknya memang tidak terlihat tetapi cukup mematikan. Efeknya tidak ada mimisan, bengep, seperti intimidasi fisik tapi nikam banget kedalam jiwa, kena banget. Oleh sebab itu biasanya tingkat bunuh diri paling banyak berasal dari cyber bullying dan verbal bullying, (Liza Marielly Djaprie dalam cnnindonesia.com, 14 Januari 2016).

Faktor-faktor yang menyebabkan terjadinya bullying telah diteliti oleh Saifullah (2016) adalah; 1) terpengaruh oleh teman sebaya; siswa-siswa terpengaruh oleh teman-temannya untuk ikut-ikutan kelompok/grup pertemanan untuk berbuat usil dan mengolok-olok. 2) pola asuh orang tua; kurangnya perhatian orang tua dilingkungan keluarga dalam membentuk tingkah laku yang baik. 3) sekolah yang kurang mendukung; sekolah tidak mempedulikan atau kurang menindak lanjuti siswa-siswa yang nakal, disiplin sekolah kurang. Selain itu faktor resiko anak menjadi korban bullying menurut Yuyarti (2018:171-172) yaitu; 1) dianggap berbeda, misalnya memiliki ciri fisik tertentu yang mencolok seperti lebih kurus, gemuk, tinggi atau pendek dibandingkan dengan yang lain, berbeda dalam status ekonomi, memiliki hobi yang tidak lazim, atau menjadi siswa siswi baru. 2) dianggap lemah atau tidak dapat membela diri, 3) memiliki rasa percaya diri yang rendah. 4) Kurang populer dibanding dengan yang lain, tidak memiliki banyak teman.

Praktik bullying yang jelas sering terjadi di sekolah yaitu bullying fisik dan bullying verbal. Beberapa kasus bullying fisik telah terjadi beberapa contoh kasus diantaranya yang pertama yaitu: seorang siswa kelas VII Sekolah Menengah Pertama (SMP) Negeri 16 Kota Malang - Jawa Timur, dua ruas jari tengahnya harus diamputasi karena menjadi korban bullying teman-temannya. Yang kedua, seorang siswa Sekolah Menengah Atas (SMA) di Pekan Baru. Berawal dari bercanda, ada kata-kata yang tidak bisa diterima oleh temannya sehingga merasa tersinggung dan emosi lalu melakukan kekerasan, pelaku memukul korban dengan kayu bingkai foto kemudian menarik kepala korban dan dibenturkan ke lutut hingga mengalami patah tulang hidung dan dipaksa mengaku bahwa dirinya terjatuh. Yang ketiga, siswi SMP berkebutuhan khusus di Purworejo, dirundung oleh teman-temannya karena dimintai uang namun tidak diberi, akibatnya dia dipukul dengan gagang sapu dan ditendang, selain itu teman-temannya mengambil paksa uang dia dan mengancam jika dia melapor kepada guru (Kompas.com, 8 Februari 2020). Yang keempat seperti yang terjadi di SMAN 1 Bangkinang, Riau, seorang siwa kelas $\mathrm{X}$ bunuh diri di sungai karena sering dirundung teman-temannya dengan sebutan anak orang gila sebab bapaknya 
mengidap penyakit gangguan jiwa yang terkadang kambuh (detiknews.com, 1 Agustus 2017). Yang kelima, seorang siswa SMP yang pernah menerima hadiah sepeda dari Presiden Jokowi Dodo di Kupang, Nusa Tenggara Timur (NTT), telah melakukan bunuh diri karena selalu dibully teman-temannya perihal ayahnya yang dipenjara karena membunuh ibunya (HaiBunda.com, 22 Oktober 2019).

Maka dari itu, kami dari tim Program Pengabdian kepada Masyarakat (PkM), Universitas Pamulang (UNPAM) yang berjumlah 5 orang dosen dan 12 mahasiswa/i ingin turut serta berkontribusi dalam memberikan pendidikan karakter dengan memberi penyuluhan kepada siswa - siswi di TBM (Taman Baca Masyarakat) terkait bullying, kami memilih lokasi di TBM karena banyak siswa yang berkumpul disana, baik dari mulai tingkat Taman Kanak - Kanak sampai Sekolah Menengah Atas. Taman Baca Masyarakat (TBM) selain menjadi tempat untuk membaca, disana juga diadakan kegiatan - kegiatan pembelajaran seperti mendongeng, kreasi, seni, dan belajar bersama dengan tutornya. Menurut database pengurus TBM, terdapat 70 orang siswa - siswi yang datang ke TBM untuk membaca, mengerjakan tugas, dan bermain. Hal ini menjadi sasaran yang pas untuk diberikan penyuluhan. Selain itu karena melihat lokasi kampus yang tidak jauh dengan lokasi Taman Bacaan Masyarakat, yaitu di Kolong Jembatan Ciputat, Jl. Dewi Sartika, Cipayung, Kecamatan Ciputat Kota Tangerang Selatan, Banten.

Adapun luaran yang dihasilkan oleh TIM Pengabdian kepada Masyarakat (PKM) kami adalah berupa hasil fisik dan hasil non fisik. Hasil fisik yaitu berupa poster sebagai hasil karya anak-anak dnegan tema anti bullying dan poster bertema kasih sayang serta peduli terhadap teman. Sedangkan hasil non fisik yaitu berupa pemahaman akan bahayanya bullying dari hasil penyuluhan dan diskusi bersama anak2, pengetahuan akan bahayanya bullying. Hasil non fisik lainnya adalah: vocabulary dan expressions dalam bahasa Inggris. Luaran Berdasarkan solusi permasalahan yang diusulkan Tim Pengabdian kepada Masyarakat (PkM) untuk anak-anak di Taman Baca Masyarakat Kolong Jembatan Ciputat sebagai berikut: anak-anak memahami tentang bahaya bullying sehingga mengurangi bullying di sekolah meningkatkan kepedulian anak-anak terhadap teman temannya, dan bergaul dengan baik dan kooperatif.

\section{B. Pelaksanaan dan Metode}

Pelaksanaan kegiatan Pengabdian kepada Masyarakat yang dilakukan oleh dosen-dosen program studi Sastra Inggris dengan judul kegiatan "Say No to Bully! Kind Words Bulid Beautiful World" berlokasi di Taman Baca Masyarakat di Kolong Jembatan Ciputat, pada hari Jumat-Minggu tanggal 06-08 Maret 2020. Terkait bullying, kami memilih lokasi di TBM karena banyak siswa -siswi yang berkumpul disana, baik dari mulai tingkat Taman Kanak - Kanak sampai Sekolah Menengah Atas. Taman Baca Masyarakat (TBM) selain menjadi tempat untuk membaca, disana juga diadakan kegiatan - kegiatan pembelajaran seperti mendongeng, kreasi, seni, dan belajar bersama dengan tutornya. Menurut data base pengurus TBM, terdapat 70 orang siswa - siswi yang datang ke TBM untuk membaca, mengerjakan tugas, dan bermain. Hal ini menjadi sasaran yang tepat untuk diberikan penyuluhan. Selain itu karena melihat lokasi kampus yang tidak 
jauh dengan lokasi Taman Bacaan Masyarakat, yaitu di Kolong Jembatan Ciputat, Jl. Dewi Sartika, Cipayung, Kecamatan Ciputat Kota Tangerang Selatan, Banten.

Ada empat tahapan metode pelaksanaan yaitu, warming up, main activity (pemberian materi - materi anti bulying), pembuatan poster anti bulying, dan penampilan. Metode-metode tersebut akan dijelaskan sebagai berikut:

1. Pendampingan

Pembukaan diisi oleh pendampingan yang dilakukan dengan brainstorming. Pada kegiatan brainstorming ini siswa siswi Taman Kanak - kanak sampai Sekolah Menengah Pertama diberi game, bernyanyi bersama, dan dongeng anti bullying. Hal ini dilakukan untuk menambah semangat anak - anak dan juga membuka mindset mereka terhadap bullying.

2. Penyuluhan anti bullying

Penyuluhan dilakukan dengan menyampaikan materi bullying. Pada tahap ini, siswa - siwi di TBM diberi pemahaman terkait bullying, diantaranya :

- Menjelaskan pengertian bullying

- Menjelaskan jenis - jenis bullying

- Menjelaskan dampak dari bullying

- Menjelaskan bagaimana respon yang efektif ketika menjadi korban bullying atau melihat teman- temanya menjadi korban bullying.

- Menjelaskan cara yang efektif untuk mencegah bullying.

- Memberi pemahaman kepada siswa- siswi bahwa kita adalah makhluk sosial, yang artinya kita butuh teman untuk saling membantu dan bekerjasama.

- Memberi pemahaman kepada siswa - siswi bahwa kita adalah sama. Hal ini disampaikan agar tidak ada senioritas, atau merasa paling dan merendahkan orang lain. Memberi penjelasan kepada siswa-siswi bagaimana mengekspresikan sikap marah terhadap teman agar tidak langsung menyerang dengan cara membabi buta, tetapi dengan mencari kejelasan tentang permasalahan yang sedang terjadi hingga jelas benar faktanya, lalu bicarakan dari hati ke hati dengan yang bersangkutan.

3. Membuat poster anti bullying.

Menerapkan penyuluhan anti bullying selain dengan pemberian materimateri bullying juga dilakukan dengan pembuatan poster. Siswa-siswi TK sampai anak-anak SMP ditugaskan untuk membuat poster anti bullying, namun terdapat perbedaan antar siswa TK sampai SMP, sebagai berikut:

- Kelompok TK

Oleh karena anak-anak TK masih dalam proses belajar mengenal huruf, maka untuk kegiatan ini mereka hanya ditugaskan membuat poster dengan cara menempelkan huruf huruf agar membentuk kata - kata anti bullying pada media kardus yang telah dilapisi kertas karton. Media kardus dan huruf-huruf yang akan ditempel telah dibuat oleh mahasiswa PKM dengan menggunakan kertas origami yang berwarna-warni, Misalnya :
-Kind
- lovely
-Friendship
-You are special 
Kata-kata anti bulying ditulis dengan bahasa Inggris karena disamping penyuluhan anti bullying juga bertujuan untuk menambah kemampuan bahasa inggris pada siswa- siswi yang mengikuti kegiatan penyuluhan anti bullying di TBM. Dalam hal ini, Khususnya untuk siswa- siswi TK bertujuan untuk menambah kosakata bahasa Inggris.

- Kelompok SD

Pada kelompok SD, siswa - siswi ditugaskan dengan tugas yang sama, akan tetapi kata kata anti bulying lebih panjang dalam bentuk kalimat. Misalnya :

- Do not bully your friends!

- Do not be sad, you are my friend

- we are friend forever!

- You and I always together!

- Kelompok SMP

Untuk kelompok anak-anak SMP, tim PKM hanya menyediakan alat- alat dan bahan bahan untuk membuat poster dan mereka mengkreasikannya sendiri.

4. Penampilan

Pada tahap ini, siswa- siswi menampilkan hasil karya posternya dengan yelyel anti bullying yang telah dibuat.

5. Penutupan

Pada tahap ini, tim PkM mengevaluasi peserta dengan menanyakan hal-hal apa saja yang telah didapat pada kegiatan ini? dan diberi pesan- pesan motivasi.

Adapun rincianacara pelaksanaan kegiatan pengabdian masyarakat di Taman Baca Masyarakat (TBM) Ciputat adalah sebagai berikut:

Hari Jumat tanggal 06 Maret 2020:

1. Pembukaan oleh pembawa acara dari pihak TBM (Pukul 14.00-14.05WIB)

2. Sambutan oleh ketua PkM (Pukul 14.05-14.10 WIB)

3. Warming Up oleh mahasiswa \& dosen dan siswa TBM (Pukul 14.10-14.30 WIB)

4. Main activity -Bermain game anti-bullying oleh mahasiswa dan siswa TBM diawasi oleh dosen (Pukul 14.30-14.50 WIB)

5. Bernyanyi bersama dan dongeng anti bullying oleh mahasiswa dan siswa TBM diawasi oleh dosen (Pukul 14-50-15.40 WIB)

6. Penutupan oleh mahasiswa \& dosen (Pukul 15.40-16.00 WIB)

7. Evaluasi oleh pengurus TBM, dosen dan mahasiswa

Hari Sabtu tanggal 07 Maret 2020

1. Pembukaan oleh pembawa acara dari pihak TBM (Pukul 14.00-14.05WIB)

2. Sambutan oleh ketua PkM (Pukul 14.05-14.10 WIB)

3. Warming Up dan brainstorming oleh mahasiswa \& dosen dan siswa TBM (Pukul 14.10-14.30 WIB) 
4. Main activity- Penyuluhan anti-bullying oleh mahasiswa dan siswa TBM diawasi oleh dosen (Pukul 14.30-14.50 WIB)

5. Menjelaskan pengertian, jenis, dampak dari bullying dan cara efektif untuk mencegah bullying oleh mahasiswa dan siswa TBM diawasi oleh dosen (Pukul 14-50-15.40 WIB)

6. Penutupan oleh mahasiswa \& dosen (Pukul 15.40-16.00 WIB)

7. Evaluasi oleh pengurus TBM, dosen dan mahasiswa

Hari Minggu tanggal 08 Maret 2020

1. Pembukaan oleh pembawa acara dari pihak TBM (Pukul 14.00-14.05WIB)

2. Sambutan oleh ketua PkM (Pukul 14.05-14.10 WIB)

3. Warming Up mahasiswa \& dosen dan siswa TBM (Pukul 14.10-14.30 WIB)

4. Main activity- membuat poster anti-bullying oleh mahasiswa dan siswa TBM diawasi oleh dosen (Pukul 14.30-14.50 WIB)

5. Siswa- siswi TK sampai anak-anak SMP ditugaskan untuk membuat poster anti bullying oleh mahasiswa dan siswa TBM diawasi oleh dosen (Pukul 1450-15.20 WIB)

6. Performance----Siswa menunjukkan hasil karya posternya. Terutama siswa SMP menampilkan poster dengan yel-yel kelompok mereka. oleh siswa TBM diawasi oleh dosen (Pukul 15.20-15.40 WIB)

7. Penutupan oleh mahasiswa \& dosen(Pukul 15.40-16.00 WIB)

8. Review oleh pengurus TBM, dosen \& mahasiswa

\section{Hasil dan Pembahasan}

Pelaksanaan Kegiatan Pengabdian kepada Masyarakat (PkM) yang dilaksanakan oleh Tim PkM Program Studi Bahasa Inggris melalui LPPM UNPAM yang mengusung tema kegiatan "Say No to Bully! Kind Words Build Beautiful World" kegiatan Taman Baca Masyarakat (TBM) di Kolong Jembatan Ciputat, J1. Dewi Sartika, Cipayung, Kecamatan Ciputat, Kota Tangerang Selatan, Banten telah dilaksanakan secara lancar pada hari Jumat sampai dengan Minggu, tanggal 06-08 Maret 2020 dengan jumlah peserta sebanyak 70 anak. Dalam pelaksaannya kegiatan PkM ini ada 4 metode pelaksanaan yaitu warming up, main activity (pemberian materi - materi anti bullying), pembuatan poster anti bullying, dan penampilan. Pada setiap tahap dapat dilihat dan dihasilkan luaran yang diharapkan seperti:

\section{Pendampingan}

Hasil yang dilihat dari kegiatan ini adalah keceriaan dan keakraban antar siswa yang terlihat dari suasana menyenangkan dan positif. Dalam kegiatan ini bernyanyi bersama-sama dan menari mengikuti lagunya. Kadang dalam bernyanyi anak-anak bergandengan tangan dan saling bersahutan. Suasana tersebut dapat dilihat pada foto berikut: 
http://openjournal.unpam.ac.id/index.php/ACB/issue/view/605/showToc

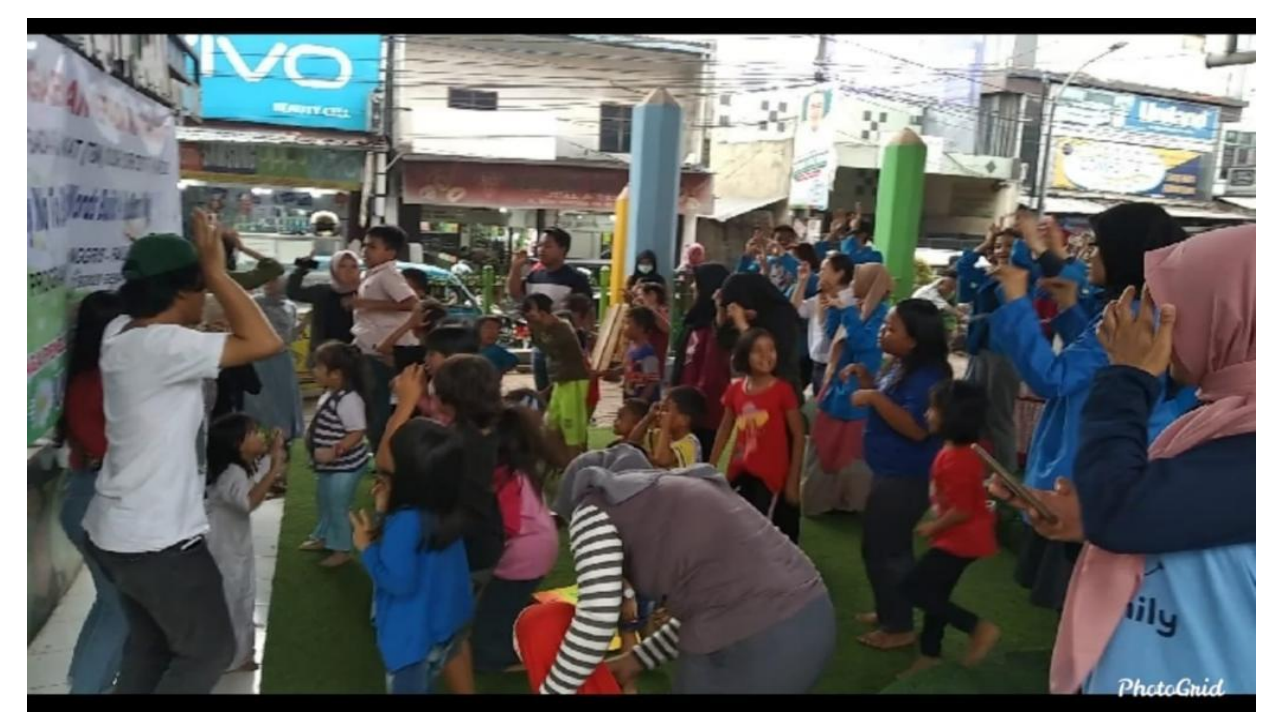

Gambar 1. Bernyanyi bersama antara Tim PkM dan siswa-siswi TBM

2. Penyuluhan anti bullying

Pada tahap ini mahasiswa-mahasiswa jurusan Sastra Inggris Universitas Pamulang memberikan pendekatan dan materi tentang bullying. Dapat dilihat dari kegiatan bahwa tim mahasiswa mampu memberikan pemahaman akan bullying dengan melihat respon dari siswa-siswa. Sebagai contoh ketika mahasiswa bertanya "Siapa yang pernah di bully?". Banyak siswa yang menjawab "saya kak", "Diapain?" kata kakak, "Ditoyor kepalanya terus dikatain goblok" jawab seorang siswa, "Lalu kamu balas ga?" tanya kakak, "Engga kak" jawab siswa, "Bagus karena kalau kamu balas toyor dan katain juga berarti kamu sama dengan dia" kakak menjelaskan, "Jadi kalau kamu mengalami bully kamu lapor sama orang tua atau guru ya. Jangan disimpan sendiri ya" kata kakak. Lalu tahap ini berlanjut dengan bahasan-bahasan lain seperti bagaimana caranya melindungi diri dari bully dan bagaimana agar siswa tidak jadi orang yang melakukan perundungan Penyuluhan anti bullying dapat dilihat pada foto berikut:

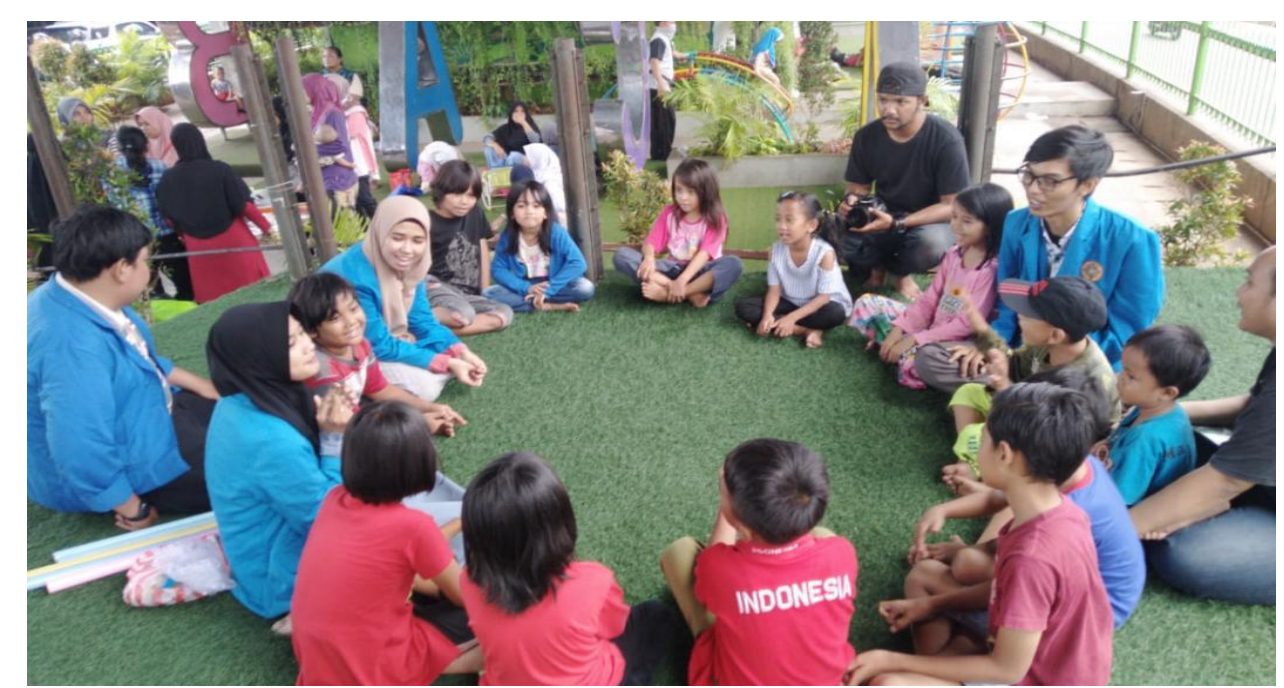

Gambar 2. Tim PkM memberikan penyuluhan kepada siswa-siswi TBM

3. Membuat poster anti bullying. 
Pada tahap ini semua mahasiswa dan dosen Sastra Inggris Universitas Pamulang mendampingi siswa-siswi TBM dalam menyusun kata atau kalimat baik dan anti bullying dalam bahasa Inggris Kegiatan ini memang ditujukan untuk memberikan pembelajaran bahasa Inggris sekaligus dalam membahas topik anti bullying sehingga hasil yang didapatkan efektif dan bermanfaat. Hasil dari tahap pembuatan poster dapat dilihat pada gambar berikut:

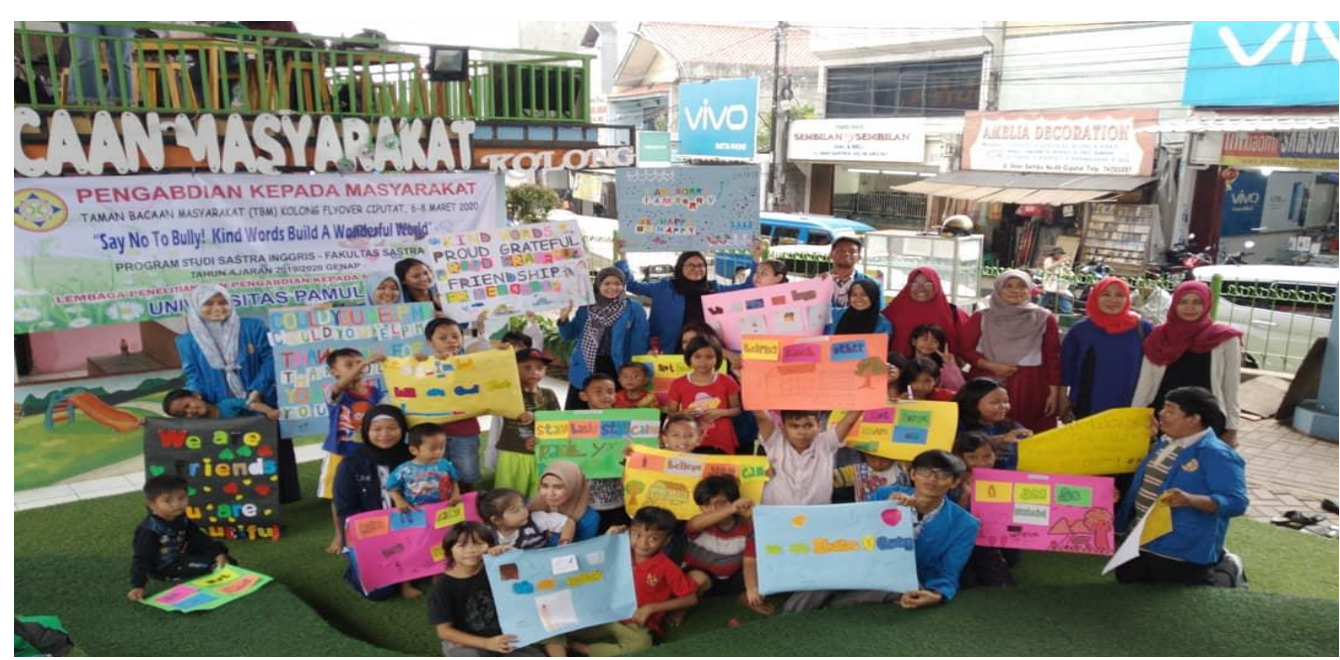

Gambar 3. Tim PkM mendampingi siswa-siswi TBM dalam membuat poster anti bullying

\section{Penutup Simpulan}

Pelaksanaan kegiatan Pengabdian kepada Masyarakat(PkM)oleh Lembaga Penelitian dan Pengabdian Masyarakat (LPPM) Universitas Pamulang yang dilakukan oleh dosen-dosen program studi Sastra Inggris dengan judul kegiatan "Say No to Bully! Kind Words Build a Wonderful World" dengan tujuan untuk mencegah tindakan bullying telah berjalan dengan lancar dan mendapat sambutan hangat dari tempat pelaksanaan kegiatan ini yaitu Taman Bacaan Masyarakat (TBM) Kolong Jembatan Ciputat.

Siswa-siswa pada Taman Baca Masyarakat (TBM) Kolong Jembatan Ciputat dapat membuka wawasan melalui penyuluhan dilakukan dengan menyampaikan materi tentang bullying sehingga mereka dapat menjelaskan pengertian bullying, menjelaskan jenis - jenis bullying dan menjelaskan dampak dari bullying. Selanjutnya mereka juga mengerti bagaimana respon yang efektif ketika menjadi korban bullying atau melihat teman -temanya menjadi korban bulying menjelaskan cara yang efektif untuk mencegah bullying. Memberi pemahaman kepada siswa -siswi bahwa kita adalah makhluk sosial, yang artinya kita butuh teman untuk saling membantu dan bekerjasama, memberi pemahaman kepada siswa siswi bahwa kita adalah sama (hal ini disampaikan agar tidak ada senioritas, atau merasa paling dan merendahkan orang lain), memberi penjelasan kepada siswa - siswi bagaimana mengekspresikan sikap marah terhadap teman 
agar tidak langsung menyerang dengan cara membabi buta, tetapi dengan mencari kejelasan tentang permasalahan yang sedang terjadi hingga jelas benar faktanya, lalu bicarakan dari hati ke hati dengan yang bersangkutan.

\section{Saran}

Dengan diadakan penyuluhan anti bullying pada program PkM ini, diharapkan kasus bullying tidak lagi ada, oleh karena itu banyak peran yang terlibat untuk mencegah kekerasan atau anti bullying, diantaranya,

1. Pihak orang tua, seperti kita ketahui,tentunya tidak ada lagi yang bisa turut mengendalikan dan membentuk perilaku anak selain orang tuanya. Baik itu dalam kaitannya ketika anak menjadi korban ataupun menjadi pelaku. Orang tua dapat menjadi pihak yang meluruskan perilaku bullying atau justru mendukungnya dengan pola asuh yang mereka terapkan kepada anak di rumah. Orang tua dapat menjadi jembatan untuk menyelesaikan kasus bullying yang dilakukan anak ataupun jika anaknya menjadi korban bullying terutama ajak anak ekplorasi kegiatan yang berhubungan dengan empati agar membentuk kepribadian yang beradab.

2. Selain itu pihak sekolah tidak hanya fokus pada prestasi siswa, namun harus juga berkonsentrasi pada kebutuhan emosional dan sosial seluruh siswa. Sebaiknya pihak sekolah baik guru, maupun kepala sekolah berpartisipasi membuat diskusi kelompok mingguan dengan siswa untuk berbicara tentang emosi mereka dan masalah sosial yang mereka alami dapat membuat mereka belajar keterampilan untuk mengekspresikan emosi secara positif, dan mampu memiliki strategi yang baik untuk menyelesaikan konflik. Ketika masalah yang bermasalah muncul dalam diskusi ini, anak kemudian dapat menerima bantuan tindak lanjut dari tenaga profesional di sekolah.

\section{Ucapan Terima Kasih}

1. Terima kasih yang sebesar- besarnya kepada Allah SWT, Yang telah memberikan kesehatan dan ridho-Nya sehingga kami dapat melaksanakan PkM ini dengan baik dan lancar.

2. Terimakasih kepada UNPAM dan LPPM UNPAM yang menyediakan fasilitas dan kesempatan sehingga kami dapat melaksanakan PkM ini dengan baik, lancar dan terarah.

3. Terima kasih kepada pihak Taman Bacaan Masyarakat (TBM) Kolong Jembatan Ciputat, Jl. Dewi Sartika, Cipayung, Kecamatan Ciputat Kota Tangerang Selatan, Banten. 


\section{DAFTAR PUSTAKA}

Anggraeni, Deni Tri. dkk. 2016. Validasi Program Remaja "STOP" (Sadar, Tolong, dan Perangi) Bullying untuk Mengurangi Intensi Perilaku Bullying Pada Siswa SMP. Gajah Mada Journal of Professional Psychology (GamaJJP).

Vol2,

No.2.hhtps://jurnal.ugm,ac,id/gamajjp/article/View/33359. (diakses 1 Maret 2020).

Karnesya, Annisa. 2019. Siswa Penerima Sepeda Jokowi Bunuh Diri, Dibully Karena Ayah Bunuh Ibu. HaiBunda. https://www.haibunda.com/parenting/20191020164151-62-62860/siswapenerima-sepeda-jokowi-bunuh-diri-dibully-karena-ayah-bunuh-ibu. (diakses 1 Maret 2020)

Kompas.com. 2020. 4 Kasus Bullying di Sejumlah Daerah, Dibanting ke Pavling, Amputasi hingga Korban Depresi Berat. https://amp.kompas.com/regional/read/2020/02/08/06060081/4-kasusbullying-di-sejumlah-daerah-dibanting-ke-pavling-amputasi-hingga. (diakses 1 Maret 2020)

Pinandhita, Vidya. 2020. Kekerasan Pada Anak Tak Menurun. Lokadata. https://lokadata.id/artikel/2020-kekerasan-pada-anak-tak-menurun. (Diakses 1 Maret 2020)

Saifullah, F. 2016. Hubungan Antara Konsep Diri Dengan Bullying Pada SiswaSiswi SMP (SMP Negeri 16 Samarinda) eJournal Psikologi, 2016, 4 (2):200-214

Setyowati, dkk. 2019. Upaya Edukasi Perilaku Anti Bullying di Era Digital Melalui Dongeng di http://uns.ac.id/id/uns-opinion/upaya-edukasi-perilakuanti-bullying-di-era-digital-melalui-dongeng.html (diakses 17 Maret 2020)

TimSejiwa. (2008). Bullying: Panduan bagi Orang Tua dan Guru Mengatasi Kekerasan di Sekolah dan Lingkungan. Jakarta: Grasindo.

TribunJabar.2017. Ayo Kenali Jenis - Jenis Bullying, Begini Pembagian Macamnya.https://jabar.tribunnews.com/2017/07/24/ayo-kenali-jenis-jenisbullying-begini-pembagian-macamnya (Diakses 10 Maret 2020)

Wahyuni, Tri. 2016. Kekerasan Verbal Lebih Berbahaya Dibanding Fisik. CNN Indonesia. https://m.cnnindonesia.com/gaya-hidup/2016113210042-255104124/kekerasan-verbal-lebih-berbahaya-dibanding-fisik. (diakses 1 Maret 2020)

Yuyarti. 2018. Mengatasi Bullying Melalui Pendidikan Karakter. Jurnal Kreatif, $8(2), 168-173$. 